\title{
El enriquecimiento sin causa en el contexto del contrato: a propósito del pago en exceso
}

Abogado por la Universidad de Lima. Magíster en Derecho con mención en Derecho Civil y candidato a Doctor por la

Pontificia Universidad Católica del Perú. Profesor de Derecho Civil en la Facultad de Derecho de la Universidad de Lima y en la Pontificia Universidad Católica del Perú.

SUMARIO:

I. Introducción.

II. La extensión objetiva del convenio arbitral.

III. Las fuentes de las relaciones obligatorias.

IV. El pago indebido como fuente heterónoma de relaciones obligatorias.

1. Algunas consideraciones generales sobre el pago indebido.

1.1. La atribución o desplazamiento patrimonial.

1.2. La ausencia de causa.

1.3. El error.

2. El pago en exceso.

V. El enriquecimiento sin causa en el ámbito de los contratos: un poco de historia. 


\section{RESUMEN:}

El autor a través de este artículo pretende demostrar cómo es que dentro del ámbito de los contratos se originan pretensiones restitutorias que tienen como fundamento relaciones obligatorias generadas en principio por fuentes heterónomas como el convenio arbitral, profundizando su análisis concretamente del pago en exceso.

Palabras clave: obligaciones contractuales, relaciones obligatorias, pago indebido, responsabilidad civil, pago en exceso, enriquecimiento sin causa.

\section{ABSTRACT:}

Through this article the author intends to demonstrate how restitutionary claims originate in contracts, which are based on compulsory relations generated by heteronomous sources such as the arbitration agreement, deepening his analysis on excess payment.

Keywords: contractual obligations, compulsory relationships, undue payment, civil liability, excess payment, unjust enrichment.

"Nam hoc natura aequum est neminem cum alterius detrimento fieri locupletiorem -Es de justicia natural que nadie se enriquezca a costa de otro-"

\section{INTRODUCCIÓN}

Supongamos que la empresa $X$ celebra un contrato con la empresa Y. En virtud de dicho contrato la empresa $X$ debe pagar a la empresa $Y$ una determinada suma de dinero. En la fecha prevista en el contrato la empresa $X$, por error, realiza un pago en exceso a la empresa Y. ¿Qué vía tiene la empresa $X$ para reclamarle a la empresa $\mathrm{Y}$ la restitución de lo pagado en exceso?

Ahora, asumamos que la empresa $\mathrm{X}$ considera que, por alguna de las causales previstas en el artículo 219 del Código Civil, el contrato es nulo. Interpone una demanda para que se declare la nulidad del contrato y, además, reclama la restitución del bien que entregó en virtud del contrato. ¿Cuál es la vía que tiene la empresa $X$ para pretender la restitución del bien?

Pensemos que por un supuesto incumplimiento de la empresa $Y$, la empresa $X$ resuelve el contrato a través del mecanismo de la resolución por intimación. La empresa $Y$ considera que no ha incumplido e interpone una demanda para que se declare ineficaz la resolución. La empresa X, por su parte, reconviene pretendiendo que se declare que el contrato fue correctamente resuelto - pretensión meramente declarativa- $y$, además, pretende la restitución del bien que entregó. ¿Cuál es la vía que tiene la empresa X para pretender la restitución del bien?

Las pretensiones restitutorias antes señaladas tienen como fundamento una relación obligatoria de fuente heterónoma: el pago indebido. Pero, además, tienen una particularidad: se dan dentro del ámbito de un contrato.

Si en dicho contrato se hubiera previsto, en forma de cláusula, un convenio arbitral. ¿El árbitro sería competente para resolver las pretensiones restitutorias en los tres casos planteados?

Algunos autores sostienen que la única relación jurídica determinada a la que se refiere el convenio arbitral bajo examen es la derivada del contrato donde se ha insertado el convenio arbitral' y añaden:

“La referencia a cualquier controversia

1. WONG ABAD, Julio. "Presupuestos adicionales de obra, enriquecimiento sin causa y cláusula arbitral en los contratos administrativos. A propósito de una discusión entre (algunos) jueces y (algunos) árbitros". En: Jus. Jurisprudencia, 9. Lima, p. 97. 
derivada de la ejecución no puede, desde este punto de vista, más que referirse a la relación jurídica contractual, pues si hubiera querido incluir la relación jurídica de enriquecimiento sin causa -inexistente y absolutamente eventual al momento de pactarse el convenio arbitral-su mención en el mismo debería ser expresa"2.

Para estos autores siendo el enriquecimiento sin causa una fuente heterónoma de relaciones obligatorias no está comprendida en el convenio arbitral incluido en los contratos, el cual se refiere solamente a la relación contractual surgida de dichos contratos - fuente autónoma de relaciones obligatorias-.

En el presente ensayo nos proponemos demostrar que se pueden dar dentro del ámbito de los contratos pretensiones restitutorias que tienen como fundamento relaciones obligatorias generadas de fuente heterónoma y que ellas son, en principio, arbitrables. Para ello, nos ocuparemos, concretamente del pago en exceso.

\section{LA EXTENSIÓN OBJETIVA DEL CONVENIO ARBITRAL ${ }^{3}$}

Para determinar el ámbito de aplicación del convenio arbitral en las controversias contractuales debemos remitirnos al mismo convenio arbitral que, bajo la forma de cláusula, consta en el contrato.

El numeral 1 del artículo 13 del Decreto Legislativo 1071 señala que las partes pueden someter a arbitraje todas las controversias o ciertas controversias que hayan surgido o puedan surgir entre ellas respecto de una determinada relación jurídica contractual; en tal sentido, cuando en el convenio arbitral establece que las partes someten a arbitraje cualquier controversia que pudieran surgir entre ellas, o someten a arbitraje todas las controversias que pudieran surgir entre ellas, no queda duda de que las partes decidieron someter a la competencia arbitral todas las controversias que pudieran surgir entre ellas respecto de la relación jurídica que las vincula, quedando excluidas aquellas controversias que no son susceptibles de arbitraje - numeral 1, artículo 2 del Decreto Legislativo 1071-.

Así, si las partes deciden en el Convenio Arbitral someter a arbitraje "todo litigio o controversia, derivados o relacionados con este acto jurídico (....)" —subrayado agregado-, no cabe duda alguna de que están comprendidas las pretensiones restitutorias derivadas de relaciones obligatorias de fuente contractual que se dan dentro ámbito del contrato.

Como señala Caramaschi las cuestiones extracontractuales derivadas de la relación contractual son:

"las controversias que tienen como objeto las consecuencias resarcitorias por hecho ilícito o por responsabilidad precontractual, o derivadas de actos de competencia desleal, o enriquecimiento sin causa de una parte respecto de la otra"s.

No cabe duda, tampoco, de que las propias partes pueden limitar el ámbito de operatividad del convenio arbitral limitando su aplicación solo a ciertas controversias o excluyendo expresamente aquellas controversias que, siendo susceptibles de arbitraje, las partes no desean someterla a la competencia arbitral; así, por ejemplo, podría acordarse de que no serán arbitrables las controversias relativas a las pretensiones restitutorias derivadas de relaciones

2. WONG ABAD, Julio. Op. Cit., p. 98.

3. Me remito a BARCHI VELAOCHAGA, Luciano. "El Convenio Arbitral en el Decreto Legislativo No. 1071". En: Ius et Praxis. No. 44, 2013, pp. 81-124.

4. Así la Cláusula Modelo de Arbitraje del Centro de Arbitraje de la Cámara de Comercio de Lima.

5. CARAMASCHI, Chiara. "La clausola compromissoria". En: Il Civilista. No. 1. 2007, p. 56. 
obligatorias de fuente contractual que se dan dentro ámbito del contrato ${ }^{6}$.

No sería razonable afirmar que el árbitro es competente para declarar la nulidad o la resolución del contrato, pero no lo es para ordenar la restitución de las prestaciones. Que sea competente para declarar que el pago de una determinada suma de dinero no era debida en virtud del contrato, pero que no sea competente para ordenar su restitución.

\section{LAS FUENTES DE LAS RELACIONES OBLI- GATORIAS}

Recordemos la clásica clasificación de Gayo de las fuentes de las obligaciones: contractus, quasi ex contractus, delictum y quasi ex delicto. Como bien advierte Díez-Picazo entre las obligaciones que nacen quasi ex contractu están las obligaciones nacidas de la condictio indebiti o pago de lo indebido?.

Díez-Picazo nos presentó luego una reestructuración de las fuentes de las obligaciones: "fuentes autónomas; es decir, la voluntad como fuente de relaciones obligatorias y las fuentes heterónomas, la soberanía del Estado como creadora de relaciones obligatorias" ${ }^{\prime}$.

De acuerdo con nuestro Código $\mathrm{Civil}^{9}$ entre las fuentes autónomas encontramos el contratoartículo 1351, 1402 y 1403 del Código Civil-y la promesa unilateral —artículo 1956 del Código Civil-.
Respecto a la constitución heterónoma de relaciones obligatorias, Díez-Picazo dice:

"En todos aquellos casos en que la relación obligatoria no nace de un negocio jurídico, puede hablarse de una constitución forzosa o heterónoma de la relación. La relación se crea por obra de un poder que es independiente de la voluntad de los sujetos. Naturalmente, la fuente de la obligación solo puede ser un acto de un órgano estatal que ostenta un poder suficiente y a quien el ejercicio de dicho poder le autoriza para constituir entre particulares relaciones jurídicas de Derecho Privado. Estos actos jurídicos pueden ser fundamentalmente de dos clases: actos administrativos y actos judiciales." ${ }^{10}$

Díez-Picazo considera un último grupo de fuentes de las obligaciones que son aquellas obligaciones que nacen de supuestos de hecho legalmente tipificados ${ }^{11}$. En estos casos la realización del supuesto de hecho previsto en la norma dará lugar al nacimiento de la relación obligatoria.

Entre las relaciones obligatorias que nacen de supuestos de hecho legalmente tipificados se encuentran aquellas:

"Que tienden a reparar o a restituir un equilibrio patrimonial roto como consecuencia de un acto ilícito o de una atribución patrimonial injustificada. En particular, se sitúan dentro de esta rúbrica las obligaciones na-

6. Así, por ejemplo: "Sin perjuicio de lo anterior, el enriquecimiento sin causa, así como las materias que sean de fuentes obligaciones distintas al presente Contrato no serán materia arbitrable".

7. DÍEZ-PICAZO, Luis. Fundamentos del derecho civil patrimonial. Vol. Il. Sexta edición. Madrid: Civitas. Thomson Reuters, 2009, p. 161.

8. DÍEZ-PICAZO, Luis. Fundamentos del derecho civil patrimonial. Vol. II. Op. Cit., p. 167.

9. Nuestro Código Civil no tiene una norma como el artículo 1.089 del Código Civil español que enumera las fuentes de las obligaciones: "Las obligaciones nacen de la Ley, de los contratos y cuasi contratos, y de los actos y omisiones ilícitos o en que intervenga cualquier género de culpa o negligencia."

10. DÍEZ-PICAZO, Luis. Fundamentos del derecho civil patrimonial. Vol. II. Op. Cit., p. 182.

11. Son las que tradicionalmente se conocen como obligaciones ex lege. 
cidas del enriquecimiento sin causa y las obligaciones de un reembolso de gastos o de reparación de daños y perjuicios. Son, por regla general, obligaciones de reparación, de indemnización o de restitución."12

Así pues, el pago indebido constituye una fuente heterónoma de relaciones obligatorias.

\section{EL PAGO INDEBIDO COMO FUENTE HETE- RÓNOMA DE RELACIONES OBLIGATORIAS}

\section{Algunas consideraciones generales sobre el pago indebido. ${ }^{13}$}

El artículo 1267 del Código Civil se refiere a las atribuciones patrimoniales sin causa por error del solvens; es decir, al pago indebido.

El artículo 1267 establece: "El que por error de hecho o de derecho entrega a otro algún bien o cantidad en pago, puede exigir la restitución de quien la recibió".

Como puede apreciarse el artículo citado contiene: a) un supuesto de hecho'" : "el que por error de hecho o de derecho entrega a otro algún bien o cantidad en pago" y b) una consecuencia ${ }^{15}$ : la constitución de una relación obligatoria donde quien recibe "indebidamente" - accipiens ${ }^{16}$ algún bien o cantidad queda obligado a su restitución frente a quien se lo entrega por error - solvens-.

De aquí puede afirmarse que el pago indebido - supuesto de hecho- constituye una fuente heterónoma de relaciones obligatorias - consecuencia- Como indica Díez-Picazo "en todos aquellos casos en que la relación obligatoria no nace de un negocio jurídico, puede hablarse de una constitución forzosa o heterónoma de la relación. La relación se crea por un poder que es independiente de la voluntad de los sujetos"17, ese poder es la soberanía del Estado creando relaciones jurídicas entre particulares, por ello se dice que es una constitución heterónoma de relaciones obligatorias. En concreto se trata de un supuesto legalmente tipificado ${ }^{18}$, basta que se realice el supuesto de hecho contemplado en la norma — un desplazamiento patrimonial sin causapara que se constituya la relación obligatoria independientemente de la voluntad de los sujetos de derecho. Por esta razón la mayoría de las legislaciones ubican al pago indebido, adecuadamente, en el libro de fuentes de las obligaciones y no en la parte relativa al pago como lo hace el Código Civil.

12. DÍEZ-PICAZO, Luis. Fundamentos del derecho civil patrimonial. Vol. II. Op. Cit., p. 182.

13. Me remito a BARCHI VELAOCHAGA, Luciano. "El pago indebido en el Código Civil peruano" (Primera Parte). En: lus et Praxis. No. 41, 2010, pp. 61-101 y "El pago indebido en el Código Civil peruano" (Segunda Parte). En: Ius et Praxis. No. 42, 2011, pp. 43-71.

14. De acuerdo con Rubio Correa "el supuesto es la hipótesis que formula el autor de la norma jurídica para que, de verificarse u ocurrir en la realidad, se desencadene lógico-jurídicamente la necesidad de la consecuencia". RUBIO CORREA, Marcial. El sistema jurídico. Introducción al Derecho. Lima: Fondo Editorial de la PUCP, 2004, p. 97.

15. De acuerdo con Rubio Correa: "La consecuencia es el efecto que el autor de la norma jurídica le atribuye lógico-jurídicamente a la verificación del supuesto en la realidad". RUBIO CORREA, Marcial. Op. Cit., p. 101.

16. Llamamos accipiens al sujeto que recibe el "pago indebido" y solvens a quien lo efectúa.

17. DÍEZ-PICAZO, Luis. Fundamentos del derecho civil patrimonial. Volumen I. Quinta edición. Madrid: Civitas, 1996, p. 154. También ver DÍEZ-PICAZO, Luis. "Los Ilamados contratos forzosos". En: Anuario de Derecho Civil. Madrid: 1956, fascículo 1, pp. 85-117.

18. DÍEZ-PICAZO, Luis. Fundamentos del derecho civil patrimonial. Vol. I. Op. Cit., p. 154. 
El supuesto de hecho del pago indebido comprende: a) una atribución o desplazamiento patrimonial, b) la ausencia de causa y c) el error.

\subsection{La atribución o desplazamiento patri- monial.}

La entrega a otro algún bien o cantidad constituye una atribución o desplazamiento patrimonial.

Una atribución o desplazamiento patrimonial consiste en una ventaja o beneficio de carácter patrimonial proporcionado a otra persona. Implica, por consiguiente, la alteración en la esfera patrimonial de un sujeto. Así, la entrega de un bien a -o la realización de un servicio a favor de- un sujeto de derecho constituye una atribución o desplazamiento patrimonial.

Si bien atribución y desplazamiento pueden ser entendidos como sinónimos, en estricto, el término desplazamiento es más concreto que el término atribución, ya que requiere que la citada ventaja o beneficio se materialice en un bien -o dinero-, dejando así al margen toda atribución patrimonial que implique un hacer o un no hacer.

\subsection{La ausencia de causa.}

Como dice Díez-Picazo:

"Todo desplazamiento patrimonial, todo enriquecimiento y, en general, toda atribución, para ser lícitos, deben fundarse en aquellas causas o razones de ser que el ordenamiento jurídico considera como justas. Cuando una atribución patrimonial no está fundada en una justa causa, el beneficiario de la atribución debe restituir al atribuyente el valor del enriquecimiento $y$, correlativamente, surge una acción o una pretensión, en favor de este último, para obtener o reclamar dicha restitución"m9.

Para que un desplazamiento patrimonial pueda ser calificado de pago es menester que: a) encuentre su fundamento y su razón de ser en una previa relación obligatoria - causa o título-que a través de dicha atribución se cumple y b) que concurran una serie de requisitos que se refieren a los sujetos, al objeto y a las circunstancias de tiempo y de lugar —requisitos de regularidad del pago ${ }^{20}$ -

Por lo señalado, para que un desplazamiento patrimonial sea considerado pago el desplazamiento debe ser debido; es decir, debe tener una causa la cual es comúnmente, una relación obligatoria. Así, por ejemplo, si Primus entrega a Secundus $S / 1,000.00$ realiza un desplazamiento patrimonial a favor de este último, sin embargo, para que dicho desplazamiento sea calificado como "pago" debe preexistir una relación obligatoria entre Primus y Secundus la cual constituiría la causa o título del desplazamiento patrimonial.

El pago se califica precisamente como hecho debido en cuanto constituye la actuación de la relación obligatoria y, por tanto, actuación de la posición deudora. La relación obligatoria es, entonces, el título jurídico del pago. Si para que un desplazamiento patrimonial sea pago debe existir una causa o título, entonces, un pago

19. DÍEZ-PICAZO, Luis. Fundamentos del derecho civil patrimonial. Vol. I. Op. Cit., pp. 89-90.

20. El despliegue de la plena eficacia, solutoria y satisfactiva, del acto de pago exige la concurrencia de una serie de requisitos que se refieren a los sujetos, al objeto y a las circunstancias de tiempo y de lugar.

a) Desde el punto de vista de los sujetos, la regularidad del pago presupone la legitimación de la persona que lleva a cabo el pago — solvens — y en la persona que lo recibe — accipiens-

b) Desde el punto de vista del objeto, son requisitos del pago: la identidad, la integridad y la indivisibilidad.

c) Desde el punto de vista de las circunstancias de tiempo y de lugar, el pago exige que el tiempo y el lugar en que se realice sean exactos o por lo menos adecuados. 
siempre es debido; hablar de pago indebido resulta siendo contradictorio así, quizá, resulte más adecuado referirse a atribuciones o desplazamientos patrimoniales sin causa ${ }^{21}$.

Los desplazamientos patrimoniales requieren, como hemos dicho, de una causa que los justifique jurídicamente. De acuerdo con Trimarchi ${ }^{22}$ los desplazamientos patrimoniales injustificados pueden verificarse como consecuencia de:

a) Apropiaciones ilícitas, o bien por el empleo de violencia, amenazas o engaños. En este caso las consecuencias se eliminan, en lo posible, mediante el mecanismo de la responsabilidad civil.

b) Hechos que no son ilícitos y no son fuente de responsabilidad por daños. Así, por ejemplo, puede tratarse:

(i) De hechos del mismo empobrecido, quien por error entregue a otro sujeto un bien no debido;

(ii) De un hecho de la naturaleza, como la avulsión -artículo 940 del Código Civil-; o,

(iii) De un hecho del enriquecido sin ser fuente de responsabilidad civil por los daños, así, por ejemplo, el consumo de buena fe de un bien ajeno.

Cuando los desplazamientos patrimoniales se producen por hechos que no son ilícitos y no son fuente de responsabilidad por daños ${ }^{23}$, el derecho no impone al enriquecido de buena fe, como señala el autor italiano ${ }^{24}$, el resarcimiento del daño, pero le impone la obligación de pagar al empobrecido una indemnización dentro de los límites de su enriquecimiento. En este sentido Gallo señala:

"La responsabilidad civil busca de remediar los daños derivados de la comisión del ilícito; la acción de enriquecimiento tiene, en cambio, como punto de referencia el provecho obtenido mediante un hecho injusto" 25 .

$\mathrm{Si}$, por ejemplo, usando el ejemplo de Trimarchi: Primus ha utilizado el carbón de Secundus, este sufre un daño igual al valor del carbón. El enriquecimiento de Primus, en cambio, es igual al precio no pagado por igual cantidad de carbón. Si Primus no ha actuado de mala fe, no es responsable por el daño, pero está obligado según el principio del enriquecimiento sin causa, por tanto, debe pagarle a Secundus una suma de dinero igual al precio del carbón ahorrado.

21. El Código Civil español habla de "Cobro de lo indebido". Cárdenas Quirós habla de "desplazamiento patrimonial indebido". CÁRDENAS QUIRÓS, Carlos. "Hacia la reforma del Libro VI del Código Civil". En: Thémis, Revista de Derecho. No 30, p. 147.

22. TRIMARCHI, Pietro. Istituzioni di diritto privato. Decimoquinta edición. Milán: Giuffrè, 2003, p. 332.

23. Como bien lo resalta Trimarchi no todo acto dañoso es prohibido. En la vida en sociedad, es común causar daño a otros sujetos lícitamente. El desarrollo de actividades provechosas implica algún riesgo de daños a terceros - externalidades para los economistas, daños para los abogados-. No todas las externalidades deben ser internalizadas a través de la responsabilidad civil, de lo contrario, la sociedad se paralizaría por el impacto que tendría sobre cada persona la existencia de sanciones resarcitorias por todas las consecuencias dañosas, nimias o relevantes, inmediatas o remotas que involucra toda actividad humana. El éxito empresarial, por ejemplo, se manifiesta restándole clientes a sus competidores, pero ello no constituye un hecho injusto: la competencia no está prohibida, al contrario, es reconocida constitucionalmente —artículo 61- pues es útil para la sociedad. Otras veces el hecho dañoso es prohibido - hecho ilícito- y una vez cometido da lugar a responsabilidad por daños. Ver al respecto TRIMARCHI, Pietro. Istituzioni di diritto privato. Op. Cit., p. 107.

24. TRIMARCHI, Pietro. Istituzioni di diritto privato. Op. Cit., p. 332.

25. GALLO, Paolo. Arricchimento senza causa. Art. 2041-2042. II Codice Civile. Commentario. Fondata da Piero Schlesinger diretto da Francesco D. Busnelli. Milán: Giuffrè, 2003, p. 50. 
El principio general está recogido en el artículo 1954 del Código Civil que establece: "Aquel que se enriquece indebidamente a expensas de otro está obligado a indemnizarlo". Luego, tal principio se reafirma en otras disposiciones del Código Civil, particularmente, en las normas del pago indebido. Como señala Bianca:

"el pago indebido precisamente ha quedado como una particular hipótesis de enriquecimiento injustificado, caracterizada por la ejecución de una prestación no debida y del derecho de repetición respecto el accipiens" 26 .

El ordenamiento jurídico no impone al accipiens que recibe el pago indebido el resarcimiento del daño, sino lo obliga a restituir al solvens aquello en lo que se hubiese enriquecido. En tal sentido, el enriquecimiento sin causa no debe ser entendido como un tema de responsabilidad civil ${ }^{27}$.

Tradicionalmente se ha considerado el pago indebido como una especie de cuasicontrato ${ }^{28}$. Esta es herencia francesa. En efecto, en el derecho francés el pago indebido es concebido como un cuasicontrato y no como un enriquecimiento sin causa ${ }^{29}$. Esto cambiará radicalmente con la Ordennance $\mathrm{N}^{\circ}$ 2016-131 del 10 de febrero de 2016 - Journal officiel de 11 de febrero de 2016-.
Díez-Picazo, en cambio, critica la referencia que hace el artículo 1089 del Código Civil español de los cuasicontratos como fuente de obligaciones señalando: "En realidad, se trata de una categoría totalmente artificiosa, que únicamente posee una explicación histórica" ${ }^{\prime 30}$.

\subsection{El error.}

De acuerdo con el artículo 1267 del Código Civil para que se configure el pago indebido el desplazamiento patrimonial sin causa debe ser realizado por error del solvens. Por error del solvens se entiende su convicción de ejecutar una prestación debida. El error es uno de los presupuestos del pago indebido. Si se realiza un desplazamiento sin causa conscientemente - sin error- no estaríamos dentro un supuesto de pago indebido, así, por ejemplo, si Primus decide pagar a Secundus una deuda de Tertius, no es un pago indebido, sino un pago por tercero.

\section{Según Díez-Picazo:}

"en los casos en que el pago de lo indebido ha sido realizado conscientemente, de acuerdo con esta tradición, no se le puede suponer otra intención que la de realizar una liberalidad"31; $^{\prime \prime}$

no obstante, más adelante el autor español reconoce la posibilidad que el solvens realice la

26. BIANCA, Massimo. Diritto civile. Tomo 5. Milán: Giuffrè, 1994, p. 792. En este mismo sentido TRIMARCHI, Pietro. Istituzioni di diritto privato. Op. Cit., p. 354. DÍEZ-PICAZO, Luis. Fundamentos del derecho civil patrimonial. Volumen segundo. Op. Cit., p. 516.

27. Díez-Picazo considera que no son admisibles ni la posición que fusiona el enriquecimiento dentro del resarcimiento de daños y la que establece una total y absoluta separación. En las hipótesis de enriquecimiento injustificado puede existir un daño. DÍEZ-PICAZO, Luis. Fundamentos del derecho civil patrimonial. Vol. I. Op. Cit., p. 96.

28. Ver al respecto BALLARÍN HERNÁNDEZ, Rafael. El cobro de lo indebido. Perfiles institucionales y eficacia traslativa. Madrid: Tecnos, 1985, p. 43 y siguientes.

29. Ver BECH SERRAT, Jose María. El enriquecimiento injustificado en el ámbito del contrato. Navarra: Editorial Aranzadi, Thomson Reuters, 2019, p. 69. Esto cambia radicalmente con la Ordennance N²016-131.

30. Ver DÍEZ-PICAZO, Luis. Fundamentos del derecho civil patrimonial. Vol. II. Op. Cit., p. 176.

31. DÍEZ-PICAZO, Luis. Fundamentos del derecho civil patrimonial. Vol. II. Op. Cit., p. 590. 
atribución patrimonial sin error y sin pretender llevar a cabo una liberalidad como, por ejemplo, evitar los perjuicios que de no hacer el pago se sufrirían.

De acuerdo con el artículo 1267 del Código Civil el error puede ser de hecho - errorfacti- o de derecho - erroriuris-.

El error de hecho es aquel que lleva al empobrecido - solvens - a realizar un desplazamiento patrimonial mediando una falsa representación mental o en ausencia de noción acerca de algún elemento esencial de la relación obligatoria.

El error de hecho puede distinguirse en absoluto y relativo.

En el desplazamiento patrimonial por error absoluto el solvens realiza el desplazamiento con la errónea creencia de la existencia del título, sea porque nunca existió o porque ya se extinguió.

La ausencia del título puede darse desde el origen o puede ser sobreviniente. Siguiendo a Bianca podemos distinguir los siguientes ca$\operatorname{sos}^{32}$ :

a) Por inexistencia de la relación obligatoria;

b) Por extinción previa de la relación obligatoria;

c) Por falta de legitimación del accipiens; $y$,

Por nulidad, anulabilidad, resolución y rescisión del título negocial —condictio ob causam fini$\operatorname{tam}^{33}$-.
En todos estos casos, de acuerdo con el Código Civil, el solvens incurre en error sobre la existencia del título.

En la atribución patrimonial por error relativo existe título, pero el solvens incurre en error sobre los elementos que la ley considera trascendentes ${ }^{34}$.

Los supuestos de atribución patrimonial por error relativo son, entre otros: el pago en exceso.

\section{El pago en exceso.}

El pago en exceso constituye un pago indebido. En este caso existe causa, pero el solvens entrega al accipiens una cantidad mayor a la debi$\mathrm{da}$, el error consiste precisamente en realizar el desplazamiento patrimonial con la equivocada creencia de que la cantidad debida era mayor. La obligación de restituir se refiere únicamente al exceso, el cual, precisamente, no es debido. Sirena habla de indebito parziale cuando existe título, pero preveía una prestación más limitada de aquella que ha sido recibida por el accipiens ${ }^{35}$.

No obstante, la Corte Suprema en diferentes sentencias ha considerado, sin fundamentar su posición, que el pago en exceso no es un pago indebido.

En la Casación N²303-98 publicada el 2 de enero de 2001 se señala lo siguiente:

"Que tampoco es de aplicación a este caso el artículo mil doscientos setenta y cuatro

32. Bianca no menciona la rescisión, pero nosotros la incluimos. BIANCA, Massimo. Diritto civile. Tomo V. Op. Cit., p. 795. Trimarchi si menciona la rescisión. TRIMARCHI, Pietro. Istituzioni di diritto privato. Op. Cit., p. 333.

33. En estos casos la ausencia del título puede ser ab origine, así la inexistencia o nulidad o su ineficacia - condictio indebiti sine causa - o el título puede extinguirse sucesivamente al desplazamiento patrimonial, así por anulabilidad, rescisión o resolución — condictio ob causam finitam-.

34. En este sentido BUSTAMANTE ALSINA, Jorge. Repetición del pago de lo que no se debe. Buenos Aires: Abeledo-Perrot, 1981, p. 70.

35. Sirena habla de indebito parziale. SIRENA, Pietro. "La ripetizione dell'indebito". En: Op. Cit., p. 502. 
del Código Civil que señala el plazo de cinco años para imponer la acción para recuperar lo indebidamente pagado porque se califica así al pago que no se [sic] debió haberse hecho lo que no es asimilable con el supuesto de que la empresa cobre en exceso a los usuarios que es distinto del pago de lo que no se debe o el pago que no corresponde a ninguna obligación legal y se ha hecho por error; en este caso si había obligación de pago, pero de una suma menor pudiéndose cobrar el exceso por el usuario." - subrayado agregado-.

En la Casación N 5076-2013-Lima de fecha 24 de marzo de 2015 ha señalado:

"Esta Suprema Sala Suprema [sic] ha determinado que en el presente caso se trata de un pago en exceso; por lo que, no resulta de aplicación el artículo 1274 del Código Civil (...)".

Del mismo modo, en la Casación № 7458-2013Lima afirma:

"Tampoco puede aplicarse el artículo 1274 del Código Civil, para recuperar lo indebidamente pagado, toda vez, que, [sic] la precitada norma está prevista para el supuesto regulado en el artículo 1267, respecto del pago indebido efectuado por error de hecho o de derecho a otra persona, esto es el pago que no debió hacerse, supuesto diferente al caso de autos, en el que el pago se ha efectuado al concesionario titular de la acreencia sobre la base de que ja existo error en la facturación del consumo de energía, esto es, de que sí había obligación de pago, pero de una Cuma menor, pudiendo el usuario recuperar el exceso pagado en el plazo legal señalado en el artículo 2001, inciso 1 del Código Civil, que establece el plazo de prescripción de diez años."
Como puede apreciarse de las casaciones citadas, todas distinguen el pago en exceso del pago indebido. Así, para dichas casaciones el pago en exceso supone la existencia de una obligación de pago, pero de una suma menor mientras que el pago indebido es un pago de lo que no se debe. Hay una evidente contradicción pues, usando los mismos términos, el exceso pagado no es debido. En efecto si, por ejemplo, Primus le paga a Secundus 150 cuando solo le debía 100, resulta claro que estos 100 son debidos, ¿pero los 50 pagados en exceso son debidos?

Tengo la impresión de que la Corte Suprema se ha preocupado más, en los casos resueltos en las casaciones antes citadas, por extender los plazos de prescripción de cinco años para el pago indebido —artículo 1274 del Código Civil- a 10 años -inciso 1 del artículo 2001 del Código Civil-. Ahora bien, podría pensarse que la Corte Suprema considera que en el caso concreto no existe error, que se trata de un desplazamiento patrimonial sin causa, pero sin error. En tal caso, entonces, podría entenderse que para la Corte Suprema estamos frente a un enriquecimiento sin causa -la que, además, conforme al inciso 1 del artículo 2001 del Código Civil, tiene un plazo de prescripción de 10 años-, pero no, la Corte Suprema evade calificarlo como enriquecimiento sin causa.

Resulta pues sorprendente la diferencia que hace la Corte Suprema entre pago indebido y pago en exceso, parecería - y esto sería realmente grave- que fundamente su distinción en el Código Tributario que es donde aparece la diferencia ${ }^{36}$. Así, si no se produjo el hecho imponible, por tanto, no nació la obligación tributaria y el contribuyente paga, dicho pago es indebido - pago de lo que no se debe- - Si, en cambio, el contribuyente debe, pero paga un monto mayor al debido, entonces, se trata de un pago en exceso ${ }^{37}$. Ahora

36. Artículo 38.- Devolución de pagos indebidos o en exceso.

37. Ver al respecto, ROBLES MORENO, Carmen del Pilar y HUAPAYA GARRIAZO, Pablo José. "Apuntes sobre la naturaleza de los pagos indebidos y los pagos en exceso. Una necesaria revisión de su regulación en el Código Tributario". En: Derecho \& Sociedad. No. 33, Lima; pp. 56-66. 
bien, más allá de la terminología utilizada en el Código Tributario, es evidente que en este la existencia del error no es relevante, por lo que no queda ninguna duda de que en ambos casos la restitución se basa en el enriquecimiento sin causa ${ }^{38}$.

En el derecho civil no cabe esta distinción, sea que se pague sin que exista título o que se pague con título, pero en exceso, se trata de un pago indebido si el desplazamiento patrimonial se hizo por error. En ambos casos, sea por el total o por el exceso, la condictio indebiti busca evitar que se genere un enriquecimiento sin causa; es decir, busca evitar que el accipiens se enriquezca indebidamente.

Para Pothier la acción Ilamada condictio indebiti:

"es la que se tiene cuando alguien ha pagado por error a otro, no solo una cierta suma de dinero o una cantidad de cosas fungibles, que es el caso del llamado promutuum, sino, más generalmente, cualquier cosa que creía por error deber".

Y luego enumera los casos en que a su juicio se puede suponer que hay lugar a la condictio indebiti, entre los cuales, "Cuando se paga más de los que se debía, el excedente se puede reclamar por condictio indebiti"39.

Como lo mencioné, el error en el pago indebido puede ser absoluto o relativo. En el error absoluto el solvens cree que realmente está obligado sin estarlo, en cambio, en el error relativo el solvens si está obligado, pero se equivoca respecto de alguno de los elementos, así, por ejemplo, cuando el error recae en la cantidad y se paga más de lo que se debe. El pago en exceso es un desplazamiento patrimonial sin causa y si es por error califica como pago indebido, y si no hay error, como un enriquecimiento sin causa.

A lo sumo, podría existir una diferencia respecto a la prueba del error. En efecto, de acuerdo al artículo 1273 del Código Civil ${ }^{40}$ se presume el error cuando se realiza una atribución patrimonial que nunca se debió. En tal sentido, podría pensarse que en el pago en exceso al existir título no hay tal presunción y, en tal sentido, la carga de la prueba del error corresponde a quien pretende haber efectuado la atribución patrimonial sin causa. Así, teniendo en cuenta el artículo 1229 del Código Civil ${ }^{41}$, quien pretende haber efectuado la atribución patrimonial debe probar haberla hecho y, además, debe probar el error conforme al artículo 1273 del Código $\mathrm{Civil}^{42}$. No obstante, creo que esta lectura sería errada, el exceso no se debe y, por tanto, también debería presumirse el error respecto de él.

\section{EL ENRIQUECIMIENTO SIN CAUSA EN EL ÁMBITO DE LOS CONTRATOS: UN POCO DE HISTORIA}

Como señala Meier:

38. Esto no resulta extraño. De hecho en determinados sistemas el pago indebido se subsume en el enriquecimiento injustificado. Así, por ejemplo, en el Código Civil alemán.

39. Pothier citado por DÍEZ PICAZO, Luis. "La doctrina del enriquecimiento injustificado". En: Dos estudios sobre el enriquecimiento sin causa. Op. Cit., p. 105.

40. “(...) Sin embargo, se presume que hubo error en el pago cuando se cumple con una prestación que nunca se debió o que ya estaba pagada. Aquel a quien se pide la devolución, puede probar que la entrega se efectuó a título de liberalidad o por otra causa justificada."

41. "La prueba del pago incumbe a quien pretende haberlo efectuado". No obstante, la referencia al artículo 1229 no es exacta pues no estaríamos en estricto frente a un pago. Más adecuado nos parece el artículo 1900 del Código Civil español —del cobro de lo indebido- que señala: "La prueba del pago incumbe al que pretende haberlo hecho. También corre a su cargo la del error con que lo realizó (...)"

42. "Corre a cargo de quien pretende haber efectuado el pago probar el error con que lo hizo (...)" 
"En el corazón del Derecho de enriquecimiento injustificado del civil law se encuentran las condictiones, heredadas del Derecho romano. La condictio indebiti se usa cuando el demandante realiza un pago al demandado para cumplir una obligación que de hecho no existe. La obligación de la que el demandante intenta liberarse es considerada como causa, fundamento jurídico o base del pago. Cuando la obligación no existe, el enriquecimiento carece de base y es, por tanto, injustificado. Junto a la condictio indebiti, existen otras condictiones. Las principales serían la condictio ob causam finitam, que se usa en caso de la obligación o base decaiga con posterioridad al pago, y la condictio causa data causa non secuta, que se usa cuando no ha tenido lugar el evento -externo al contrato- tenido en cuenta por las partes. ${ }^{143}$

Zimmermann plantea el siguiente caso basado en Gayo III, 91 y Gayo D. 44, 7, 5, 3:

\section{"A vende su caballo a B. Algunas semanas más tarde, él entrega el animal al comprador. Cuando el vendedor demanda al comprador el precio de compra resulta que el contrato es inválido".}

Obviamente, en dicha circunstancia A debe ser capaz de recuperar su caballo en posesión de $B$, pues sería totalmente injusto que a $B$ se le permitiera conservar el caballo sin pagar una contraprestación. La reclamación de A no puede basarse ni en un delito - delicto- ni en un contrato - contractus-. B, al recibir al equino, no actuó ilegalmente y $A$, al entregar, ha cumplido la obligación contractual a su cargo, pero no existe una obligación contractual de $B$ de devolver el caballo. Como el contrato es inválido, el vendedor mantiene la propiedad y el comprador solo ha adquirido la posesión, en tal sentido, A podrá reivindicar el animal ${ }^{44}$. Sin embargo, no siempre el vendedor podrá valerse de esta acción real.

Por ello, se requiere un remedio especial, un remedio personal basado en el hecho de que el comprador ha recibido lo que posteriormente resultó indebitum: un bien que nunca se le debió y no tiene derecho a mantener. Este remedio fue instituido por los romanos y es usualmente referido como condictio indebiti. Al respecto Zimmermann señala: "A lo largo de los siglos, se ha convertido en una de las piedras angulares de nuestra moderna ley del enriquecimiento injustificado."145

En término condictio aparece en el derecho romano como una fórmula utilizada por las partes ante el magistrado - in iure- - Un proceso podía basarse en cinco legis actiones diferentes una de las cuales fue llamada legis actio per condictionem. Este nombre deriva de condicere, que significa dar aviso - condicere autem denuntiare est prisca lingua-. ${ }^{46}$

La más importante característica de la legis actio per condictionem fue su naturaleza abstracta. La base sustantiva de la demanda, su causa debendi, nunca era mencionada; a lo que se hacía referencia era el mero hecho de que se debía una suma de dinero o un bien específico.

Posteriormente si bien desapareció la notificación - dar aviso- el nuevo remedio mantuvo el nom-

43. MEIER, Sonia. "Restitución de pagos indebidos: "factores injustos" vs. "sine causa"'”. En: Enriquecimiento injustificado en la encrucijada: historia, derecho comparado y propuestas de modernización. Navarra: Thomson Reuters. Aranadi, 2017, pp. 199-200.

44. ZIMMERMANN, Reinhard. The law of obligations. Roman Foundation of de Civilian traditions. Oxford: Oxford University Press, 1996, p. 834. Ver también, DESCHEEMAEKER, Eric. "El nuevo derecho francés del enriquecimiento injustificado". En: Enriquecimiento injustificado en la encrucijada: historia, derecho comparado y propuestas de modernización. Navarra: Thomson Reuters. Aranadi, 2017, p. 128.

45. Loc. Cit. 
bre de condictio: condictio certae pecuniae o condictio certae rei según sea el caso. Como la formula estándar no hacía mención de la causa debendi la condictio resultó aplicable a una gran variedad de situaciones. Si bien es cierto normalmente los autores centran su atención en la condictio indebiti lo cierto es que los romanos reconocían una gran variedad de otras condictiones ${ }^{47}$. ¿Cuáles eras estas otras condictiones? Pues la condictio causa data non secuta; la condictio ob turpem vel iniustam causam, la condictio sine causa y la condictio furtiva.

Al margen de la condictio ex causa furtiva que se aplicaba en los casos de robo, todos los demás reclamos de enriquecimiento se caracterizaban por el hecho que el demandante intenta reclamar lo que él ha transferido al demandado. Como señala Zimmermann:

"En términos generales, la condictio se otorga si el propósito que esta transferencia pretendía alcanzar se ha frustrado o es, por alguna razón, mal visto por la comunidad. En esta específica función, las condictiones estaban vinculadas con el sistema contractual romano"48.

Así, las principales situaciones a ser consideradas eran las siguientes: a) transferencias solvendi causa, b) transacciones ejecutadas, c) transferencias credendi causa y d) datio ob rem.

A partir de esta diversidad de condictiones el Código Civil francés adoptó un modelo fragmentado en la regulación del enriquecimiento injustificado pues establece acciones específicas distintas para el pago indebido, la gestión de negocios y la acción general de enriquecimiento sin causa. Pero, como hace notar, Basozabal Arrue esta es fragmentación es aún mayor puesto hay otros supuestos como por ejemplo el pago del tercero ${ }^{49} \mathrm{o}$ el pago al acreedor aparente ${ }^{50}$.

Díez-Picazo, siguiendo el modelo tipológico alemán ${ }^{51}$ construye tipos de condictiones: a) la

46. Si en la primera comparecencia de las partes el demandado negaba las afirmaciones del demandante de que le debía una suma de dinero o una cosa específica, el demandante "daba noticia" para aparecer nuevamente frente al magistrado dentro de 30 días. Este periodo daba la oportunidad a las partes para resolver su disputa y solo si fallaban se nombraba al juez para que el proceso pudiera comenzar en serio. ZIMMERMANN, Reinhard. Op. Cit., p. 835.

47. ZIMMERMANN, Reinhard. Op. Cit., p. 838. MEIER, Sonia. "Restitución de pagos indebidos: "factores injustos" vs. "sine causa"'". En: Op. Cit., p. 200.

48. ZIMMERMANN, Reinhard. Op. Cit., p. 841.

49. Me remito a BARCHI VELAOCHAGA, Luciano. "El pago del tercero y los mecanismos de recuperación de la pérdida patrimonial sufrida por el pago de la obligación ajena en el Código Civil peruano" (Primera Parte). En: lus et Veritas. No. 46, 2013, pp. 140-163. (Segunda Parte). En: lus et Veritas. No. 47, 2013, pp. 152-181.

50. BASOZABAL ARRUE, Xabier. "Tres modelos para una regulación actual del enriquecimiento injustificado: unitaria, tipológico, fragmentado". En: InDret, Revista para el análisis del derecho. Barcelona, 2018, p. 4.

51. Como señala Basozabal Arrue: "El modelo alemán del BGB prevé una regulación general del enriquecimiento injustificado que debe adaptarse a una realidad que presenta diversidad de tipos y situaciones; tampoco este puede evitar una cierta fragmentación, pues encontramos preceptos específicos para la gestión de negocios ajenos y para las intromisiones y mejoras que acontecen en las relaciones entre propietario y poseedor. Además, se ha desarrollado una interpretación "tipológica" de los preceptos generales que adapta su aplicación a distintos "grupos de casos", que se corresponden con diferentes "tipos" de condictio o pretensión restitutoria. La diferenciación tiene en cuenta el origen del enriquecimiento - "prestación", "intromisión", "impensa" o "regreso" - y distingue en cada caso la función que cumple la restitución y el alcance de la responsabilidad". BASOZABAL ARRUE, Xabier. "Tres modelos para una regulación actual del enriquecimiento injustificado: unitaria, tipológico, fragmentado". En: Op. Cit., pp. 4-5. 
condictio de prestación, b) la condictio por intromisión y c) la condictio por inversión o desembolso ${ }^{52}$.

En el ensayo titulado "La doctrina del enriquecimiento injustificado", Díez-Picazo se refiere a la condictio de prestación. Al respecto el desaparecido maestro español señala:

"Los casos cubiertos a través de la genéricamente llamada condictio de prestación son, como se podrá comprobar, muy numerosos. Se encuentran en este terreno la figura genérica de los pagos indebidos; las prestaciones derivadas de contrato nulo o de contrato anulado; la prestación en virtud de un contrato resuelto por incumplimiento o por desaparición de la base del negocio y las prestaciones hechas para concluir un contrato o para obtener una prestación - v. gr., la ofrecida en una promesa pública-.".53

El modelo fragmentado es el adoptado por nuestro Código Civil donde, sin embargo, es posible advertir una tendencia, aunque incipiente, hacia la unificación de las condictiones; al respecto debe tenerse en cuenta que hoy las legislaciones se encaminan, precisamente, hacia un modelo unitario ${ }^{54}$. Así, en el Código Civil encontramos básicamente, dos remedios restitutorios: uno, derivado del pago indebido condictio indebiti-y, otro, de la acción general del enriquecimiento sin causa - condictio sine causa generalis-. El elemento diferenciador es la existencia del error en el primero.

Como puede apreciarse, tanto en el modelo fragmentado francés, acogido por nuestro Código Civil, como en el modelo tipológico alemán, encontramos situaciones en el que el enriquecimiento se produce en un contexto contractual. Sin duda alguna, la más evidente es el caso del pago en exceso. Así, si en virtud de un contrato una de las partes, por error, paga de más, podrá pretender la restitución de lo pagado en exceso en base a las normas del pago indebido - condictio indebiti-. Como se ha explicado, sería injusto que se permitiera al accipiens conservar lo que recibió de más, pues este se enriquecería injustamente. Es por ello, que se pone a disposición del solvens un remedio personal basado en el hecho de que el accipiens ha recibido lo que resulta indebido: una suma de dinero que nunca se le debió y que no tiene derecho a conservar.

Finalmente, si el contrato contiene un convenio arbitral en donde las partes deciden someter a arbitraje todo litigio o controversia, derivados o relacionados de dicho contrato no cabe ninguna duda de que la pretensión restitutoria derivada de un pago en exceso - condictio indebiti- puede $-y$ debe - ser planteada en sede arbitral.

52. DÍEZ-PICAZO, Luis. Fundamentos del derecho civil patrimonial. Vol. I. Sexta edición. Madrid: Civitas. Thomson Reuters, 2007, p. 124.

53. DÍEZ-PICAZO, Luis. "La doctrina del enriquecimiento injustificado". En: Dos estudios sobre el enriquecimiento sin causa. Madrid: Civitas, 1991, p. 103.

54. El Draft Common Frame of Reference-DCFR adopta un modelo unitario; así, en el Libro VII regula el unjustified enrihment englobando todas las acciones. Hoy también en Francia a raíz de la Ordennance № 2016-131. Ver DESCHEEMAEKER, Eric. "El nuevo derecho francés del enriquecimiento injustificado" En: Enriquecimiento injustificado en la encrucijada: historia, derecho comparado y propuestas de modernización. Navarra: Thomson Reuters. Aranadi, 2017, pp. 121-167. 